"This is the accepted manuscript version of the following article: Doe, E. (2016) 'An analysis of the relationships between peer support and diabetes outcomes in adolescents with type 1 diabetes', Journal of Health Psychology, which has been published in final form at http://journals.sagepub.com/doi/abs/10.1177/1359105316656228." 


\title{
An analysis of the relationships between peer support and diabetes outcomes in adolescents with type 1 diabetes
}

\author{
Dr Emily Doe, PhD MSc MBPsS ${ }^{a}$
}

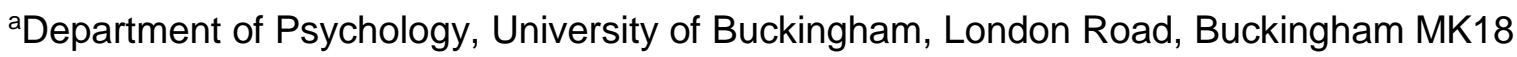
$1 \mathrm{BF}$

The present study explores the relationships between the various subtypes of global and diabetes-specific peer support and health outcomes in adolescents with type 1 diabetes. Global peer support significantly predicted self-care and $\mathrm{HbA}_{1 \mathrm{c}}$, though no associations were identified for diabetes-specific support overall, nor its factors. When comparing participants with above or below average glycaemic control, significantly greater diabetes-specific support was reported in those with poorer control. It is suggested that this may be related to feelings of nagging, in which diabetes-specific support is perceived as harassment.

\section{Key words}

Adolescent; Diabetes; Social support; Peer support; Glycaemic control

\section{Introduction}

During adolescence, a re-orientation of the social network occurs, in which peers are favoured (Helgeson, Siminerio, et al., 2009), and familial support declines (Collins and Steinberg, 2006). It is surprising, then, that the role played by peer support in health outcomes in adolescents with type 1 diabetes remains under-researched.

A systematic review of studies indicates that emotional support in the form of companionship is the most commonly reported peer support in adolescents with type 1 diabetes, with instrumental support requested and received far less (Palladino and Helgeson, 2012). Qualitative findings, however, have suggested adolescents with type 1 diabetes would prefer additional specific diabetes-orientated support, such as reminders for blood glucose testing (Lehmkuhl et al., 2009). These findings suggest that although adolescents value emotional peer support, the utility of instrumental support plays a diminished role, with differing characteristics to diabetes-specific support. Instrumental support is, therefore, potentially a support typology in which individual differences must be recognised.

These findings raise the question of comparison between diabetes-specific support and global peer support. Despite adolescents reporting more global peer support, no relationship has been identified between global peer support and self-care or glycaemic control (Helgeson et al., 2007; Helgeson, Siminerio, et al., 2009), though ecological 
momentary assessment of peer support over four days was associated with increased selfcare in females (Helgeson, Lopez, et al., 2009). A mixed body of literature therefore suggests a potential relationship between global support and self-care, but not with glycaemic control. However, many studies fail to distinguish between the various subtypes of global peer support so it cannot be determined if different support typologies present differing relationships.

When considering diabetes-specific support, results remain ambiguous. No association between diabetes-specific support and self-care has been noted in multiple studies (Greco et al., 2001; Hains et al., 2007; Naar-King et al., 2006; Pendley et al., 2002), whilst others have found evidence for a relationship to improved adherence (Kyngäs, 2000), well-being and disease adaptation (Bearman and La Greca, 2002). Such mixed literature therefore makes directional hypotheses difficult to establish. Adding further complexity, not all studies indicate a positive outcome. Diabetes-specific support has been associated with increased diabetes-related stress and poorer glycaemic control (Hains et al., 2007). This may be due to problematic support provided by peers lacking knowledge concerning type 1 diabetes (T1D) and the importance of self-care. They may therefore not provide regular or consistent diabetes-specific support, or may even have an influence that is detrimental to self-care (Thomas et al., 1997). Consequently, literature cannot elucidate the direction of any potential relationship between diabetes-specific support and diabetes outcomes.

Due to these mixed findings and lack of consideration of support subtypes, conclusions cannot be convincingly drawn as to the relationships between peer support and diabetes outcomes, leading the way for further investigation. As such, this study aims to investigate how the type of support provided by peers may moderate the relationships between peer support and diabetes outcomes.

\section{Hypotheses}

\section{Hypothesis 1: Global peer support}

i. Increased global peer support will predict improved self-care, but not glycaemic control.

ii. Emotional peer support will have a stronger relationship with self-care than instrumental peer support.

\section{Hypothesis 2: Diabetes-specific}

i. Diabetes-specific peer support will predict self-care.

ii. Diabetes-specific peer support will predict glycaemic control.

\section{Hypothesis 3: Glycaemic control}

Peer support will differ according to whether participants achieve the recommended level of glycaemic control or not. 


\section{Method}

The study was conducted in accordance with the British Psychological Society and NHS guidelines for ethical research. Ethical approval was received from the NHS research ethics board.

\section{Design and setting}

A cross-sectional research design is utilised. Participants were recruited from two general hospitals in England, via collaboration with the paediatric outpatient clinics located at each site.

\section{Participants}

Participants were aged 15-18, as previous research has indicated older adolescents report qualitatively different social support than their younger counterparts (Dovey-Pearce et al., 2007; Hanna et al., 2013). This is the age-group most likely to have re-orientated the support network to peers, and for which peer influence has become important in enacting health behaviours (Umberson et al., 2011).

Overall, 90 participants were recruited. The average age of participants was 16.59 $(S D=.96)$, with 37 males and 53 females. Regarding treatment modality, 81 participants employed injection and 9 used an insulin pump. Recent audit data suggests $5.8 \%$ of people with type 1 diabetes under the age of 20 use insulin pumps, and this is therefore slightly above the national average (Health and Social Care Information Centre, 2016).

\section{Measures}

\section{Berlin Social Support Scale}

The emotional and instrumental aspects of the Berlin Social Support Scale (BSSS; Schulz \& Schwarzer, 2003) was chosen due to its widespread use in studies with healthy participants, individuals with chronic illness and in adolescents (Pinquart and Pfeiffer, 2011). A Cronbach's $\alpha$ of .89 was achieved in the present study.

\section{Diabetes Social Support Questionnaire - Friends Version}

Seven measures of diabetes-specific support for use in adolescents with T1D currently exist, only one of which takes into account peer-support (Hanna, 2006). The Diabetes Social Support Questionnaire - Friends Version (DSSQ-Friends; Bearman \& La Greca, 2002) specifically assesses diabetes-specific support behaviours provided by peers. However, it must be considered that this measure was developed prior to the DAFNE study (DAFNE Study Group, 2002). As such, many of the items present in the DSSQ-Friends are now redundant under current healthcare guidance (National Institute for Health and Care Excellence, 2015) and were therefore removed from the measure. Reliability of this reduced scale was measured at $\alpha=.76$. 


\section{Self-Care Inventory - Revised Version}

The Self-Care Inventory - Revised Version (SCI-R; Weinger, Butler, Welch, \& La Greca, 2005) was considered favourable in the name of parsimony and due to a stronger relationship between the SCI-R and glycated haemoglobin than other self-care measures (Kichler et al., 2012). A satisfactory Cronbach's alpha was achieved with the current participant sample $(\alpha=.72)$.

\section{Glycated Haemoglobin}

A recent measure of glycated haemoglobin $\left(\mathrm{HbA}_{1 \mathrm{c}}\right)$ was provided to assess glycaemic control over the preceding 2-3 months. Currently, the WHO recommend an $\mathrm{HbA}_{1 \mathrm{c}}$ of $48 \mathrm{mmol} / \mathrm{mol}$ (6.5\%) (World Health Organisation and International Diabetes Federation, 2006) as an indicator of good glycaemic control, with an increasing $\mathrm{HbA}_{1 \mathrm{c}}$ indicating worsening control. However, the most recent National Diabetes Audit states that only $35.2 \%$ of people with T1D in England achieve this target (National Diabetes Audit, 2014). Indeed, in the present study, the average $\mathrm{HbA}_{1 \mathrm{c}}$ result was $72 \mathrm{mmol} / \mathrm{mol}(8.7 \%)$, reflecting the current state of self-care.

\section{Procedure}

The author liaised with diabetes care teams at two paediatric outpatient clinics in England. Patients conforming to the inclusion criteria were informed of the study by a member of the diabetes care team at their regular clinic appointment. Participants were provided with both written and verbal information including the purpose and nature of the research, and the criteria from which they were selected. For those aged under 16, this information was also provided to parents in order to achieve informed parental consent.

After receiving the appropriate information, participants were asked to complete the questionnaire battery. The researcher left the room during this time, and returned after all questionnaires were completed. The researcher confirmed involvement of the participant with the diabetes care team at the respective outpatient clinic, who then provided the participants' most recent $\mathrm{HbA}_{1 \mathrm{c}}$ result.

\section{Results}

Descriptive statistics are presented in Table 1. The data for all peer support measures was found to be highly positively skewed, therefore bootstrapping was used to allow for use of parametric measures. No significant differences were noted between age of participants, gender or treatment modality. 
Peer support and diabetes outcomes in adolescents with $T 1 D$

Table 1. Descriptive statistics of participants' reported emotional support, instrumental support, diabetes-specific support, self-care and glycaemic control.

\begin{tabular}{llllll}
\hline & $n$ & $\mathrm{M}$ & $\mathrm{SD}$ & Min & Max \\
\hline Emotional support & 90 & 13.36 & 2.98 & 0 & 16 \\
Instrumental support & 90 & 13.43 & 3.28 & 0 & 16 \\
Diabetes-specific support & 86 & 74.16 & 79.34 & -10 & 301 \\
Self-care & 86 & 52.65 & 8.12 & 29 & 67 \\
Glycaemic control $(\mathrm{mmol} / \mathrm{mol})$ & 86 & 72.1 & 7.87 & 36.6 & 129.5 \\
\hline
\end{tabular}

Effect sizes and their corresponding confidence intervals are presented and interpreted alongside traditional hypothesis testing methods in order to manage risk of Type I error (Garamszegi, 2006; Hedges, 2008).

\section{Hypothesis 1: Global peer support}

As seen in Table 2, linear regression revealed that increased overall global peer support predicts increased self-care accounting for $7 \%$ of variance. Contrary to the literature, however, global peer support also significantly predicts an improvement in glycaemic control, accounting for $5 \%$ of the variance in $\mathrm{HbA}_{1 \mathrm{c}}$. Due to this unexpected finding, a hierarchical multiple regression was conducted in order to control for the confounding variable of selfcare on glycaemic control. As anticipated, self-care contribution significantly to the regression model, as $F(1,84)=.12 .95, p=.001$, accounting for $13.4 \%$ of the variation in glycaemic control. Introducing global peer support explained an additional $1.4 \%$ of the variance in glycaemic control, which was non-significant as $F(1,83)=1.34, p=.250$. The unexpected relationship between global peer support and glycaemic control is, therefore, likely due to the observed association between global peer support and self-care.

The BSSS can be split into its component subscales of emotional and instrumental support. Due to multicollinearity between these subscales, linear regressions are preferred over multiple regression. As hypothesised, both emotional and instrumental support were found to predict increased self-care behaviours, accounting for $7 \%$ and $6 \%$ of variance in self-care respectively. Due to the unexpected relationship with $\mathrm{HbA}_{1 \mathrm{c}}$ indicated by the results of hypothesis 1.i, hypothesis 1 .ii was extended to include the relationship between the subtypes of global peer support and glycaemic control. Whilst emotional peer support was not a significant predictor of glycaemic control, instrumental peer support significantly accounted for $19 \%$ of the variance in $\mathrm{HbA}_{1 \mathrm{c}}$.

\section{Hypothesis 2: Diabetes-specific peer support}

As is indicated in Table 2, non-significant linear regressions were identified between diabetes-specific support, self-care and glycaemic control. The DSSQ-Friends can be 
analysed according to its component supportive behaviours; Insulin Shots, Blood Testing, Exercise and General Items. To assess if differences existed between the component supportive behaviours and diabetes outcomes, further linear regression analyses were performed (see Table 3). As with hypothesis 1.ii, linear regressions were preferred over multiple regression due to multicollinearity. Only General Items were found to be significantly related to $\mathrm{HbA}_{1 \mathrm{c}}$, accounting for $6 \%$ of variance. The General Items component refers to three statements, namely "Are available to listen to concerns or worries about your diabetes care," "Encourage you to do a good job of taking care of your diabetes" and "Understand when you sometimes make mistakes in taking care of your diabetes."

Table 2. Simple linear regressions among global peer support and diabetes-specific peer support with self-care and glycaemic control.

\begin{tabular}{|c|c|c|c|c|c|c|c|}
\hline Hypothesis & Measurements & $r^{2}$ & $95 \%$ Cls for $r^{2}$ & $F$ & $\beta$ & $t$ & $p$ \\
\hline \multirow[t]{6}{*}{ Hypothesis 1} & $\begin{array}{l}\text { BSSS } \\
\text { SCI-R }\end{array}$ & .07 & $-.03, .17$ & 6.68 & .27 & 2.58 & $.011^{*}$ \\
\hline & $\begin{array}{l}\text { BSSS } \\
\text { HbA1c }\end{array}$ & .05 & $-.04, .14$ & 4.31 & -.22 & -2.08 & $.041^{*}$ \\
\hline & $\begin{array}{l}\text { BSSS - Emotional } \\
\text { SCI-R }\end{array}$ & .07 & $-.03, .17$ & 6.43 & .26 & 2.54 & $.013^{*}$ \\
\hline & $\begin{array}{l}\text { BSSS - Emotional } \\
\mathrm{HbA}_{1 \mathrm{c}}\end{array}$ & .01 & $-.03, .05$ & .99 & -.11 & -.99 & .322 \\
\hline & $\begin{array}{l}\text { BSSS - Instrumental } \\
\text { SCI-R }\end{array}$ & .06 & $-.03, .15$ & 5.61 & .25 & 2.37 & $.020^{*}$ \\
\hline & $\begin{array}{l}\text { BSSS - Instrumental } \\
\mathrm{HbA}_{1 \mathrm{c}}\end{array}$ & .03 & $-.04, .10$ & 2.51 & -.19 & -1.95 & $.047^{*}$ \\
\hline \multirow[t]{10}{*}{ Hypothesis 2} & $\begin{array}{l}\text { DSSQ-Friends } \\
\text { SCI-R }\end{array}$ & .00 & $-.003, .005$ & .01 & .01 & .115 & .908 \\
\hline & $\begin{array}{l}\text { DSSQ-Friends } \\
\text { HbA1c }\end{array}$ & .03 & $-.04, .10$ & 2.58 & .17 & 1.61 & .112 \\
\hline & $\begin{array}{l}\text { DSSQ-Friends - Insulin shots } \\
\text { SCI-R }\end{array}$ & .03 & $-.04, .10$ & 2.67 & .17 & 1.63 & .106 \\
\hline & $\begin{array}{l}\text { DSSQ-Friends - Blood testing } \\
\text { SCI-R }\end{array}$ & .00 & $-.003, .005$ & .14 & .04 & .37 & .709 \\
\hline & $\begin{array}{l}\text { DSSQ-Friends - Exercise } \\
\text { SCI-R }\end{array}$ & .00 & $-.003, .005$ & .06 & -.03 & -.25 & .803 \\
\hline & $\begin{array}{l}\text { DSSQ-Friends - General items } \\
\text { SCI-R }\end{array}$ & .00 & $-.003, .005$ & .13 & -.04 & -.36 & .724 \\
\hline & $\begin{array}{l}\text { DSSQ-Friends - Insulin shots } \\
\mathrm{HbA1c}\end{array}$ & .02 & $-.04, .08$ & 1.30 & .12 & 1.14 & .257 \\
\hline & $\begin{array}{l}\text { DSSQ-Friends - Blood testing } \\
\mathrm{HbA1c}\end{array}$ & .02 & $-.04, .08$ & 1.69 & .14 & 1.30 & .197 \\
\hline & $\begin{array}{l}\text { DSSQ-Friends - Exercise } \\
\text { HbA1c }\end{array}$ & .03 & $-.04, .10$ & 2.81 & .19 & 1.68 & .097 \\
\hline & $\begin{array}{l}\text { DSSQ-Friends - General items } \\
\mathrm{HbA1c}\end{array}$ & .06 & $-.03, .15$ & 5.63 & .25 & 2.37 & $.020^{*}$ \\
\hline
\end{tabular}

*Significant at $p<.05$ 


\section{Hypothesis 3: Glycaemic control}

Group comparison of those with poorer or enhanced diabetes management was felt to be of value in this instance given the detrimental outcomes of poor glycaemic control (Jacobson et al., 2013). However, only $35.2 \%$ of people achieve the recommended $48 \mathrm{mmol} / \mathrm{mol}(6.5 \%)$ in the UK (National Diabetes Audit, 2014). Therefore, in order to reflect the difficulties seen in achieving optimal control, the mean value of $\mathrm{HbA}_{1 \mathrm{c}}$ found within the participant sample was used, creating a comparison between those with above or below average $\mathrm{HbA}_{1 \mathrm{c}}$ for the present group. Those with above average glycaemic control $(\leq 72.1 \mathrm{mmol} / \mathrm{mol}, 8.7 \%)$ comprised 21 males and 18 females, 34 using injection and 5 using pumps for insulin delivery. Those with below average glycaemic control ( $\geq 72.2 \mathrm{mmol} / \mathrm{mol}, 8.8 \%)$ consisted of 16 males and 31 females, with 43 using injection and 3 using pumps.

The statistical analysis suggests that those with above average $\mathrm{HbA}_{1 \mathrm{c}}$ report marginally significant greater global peer support $(M=27.60)$ than those with below average $\mathrm{HbA}_{1 \mathrm{c}}(M=26.97)$, as $t(82)=2.01, p=.048, d=.44,95 \% \mathrm{Cl}[.00, .88]$. However, this relationship is reversed when considering diabetes-specific support. Those with below average $\mathrm{HbA}_{1 \mathrm{c}}$ score significantly higher on the DSSQ-Friends $(M=106.29)$ than those with above average $\mathrm{HbA}_{1 \mathrm{c}}(M=48.73)$, as $t(79)=-3.62, p=.001, d=-.78,95 \% \mathrm{Cl}[-1.23,-.33]$, suggesting that those with poorer glycaemic control perceive greater diabetes-specific support.

\section{Discussion}

Using the results outlined in the previous section, each of the proposed hypotheses is subsequently addressed.

\section{Hypothesis 1: Global peer support}

Overall a constructive role for non-diabetes-related support in health outcomes was indicated. These findings build on those previously published by additionally distinguishing between subtypes of social support. Here, whilst emotional and instrumental predicts engagement with self-care behaviours, only instrumental support was associated with a clinically-relevant outcome.

House (1981) defines emotional support as expressions of caring, whilst instrumental support is practical in nature. Emotional support may provide adolescents with T1D with resources which enable effectual coping and increased self-efficacy, which indirectly support engagement with self-care. This has previously been seen in parental support in emerging adults with T1D (Helgeson et al., 2013). Hinder and Greenhalgh (2012) highlight the socially problematic nature of self-care, and the importance of maintaining social standing. From this perspective, emotional support may offer a resource which adolescents with T1D may utilise in their choice to engage in self-care in commonly encountered adolescent social situations. Adolescents with T1D may use self-efficacy in their decision to enact appropriate self-care in 
the presence of their social group. However, the impact of emotional support is somewhat limited, as the relationship did not extend to glycaemic control. This may be due to emotional support being an expected norm of friendship. Thus, its presence may be less noticeable and influential than support behaviours which are not expected as a condition of friendship, such an instrumental support (Helgeson et al., 2013).

Instrumental support, however, did predict glycaemic control. It should be remembered here that instrumental support is a facet of global peer support, not diabetesspecific support. As with emotional support, instrumental support may operate as a resource for increased self-efficacy, which may bleed into other areas of life, including self-care. This has been noted in previous research in participation in physical activity, particularly in males, those of low SES, and minority groups (Peterson et al., 2012). Due to beliefs that instrumental support is easily accessed and readily available, participants may be more willing to engage in self-care, knowing that assistance is available should it be required.

However, despite the measure of instrumental support referring to global behaviours, participants were not instructed to exclusively recall instances of instrumental support that were unrelated to T1D in order to avoid counter-intentional cues. As such, it is possible that the instances which participants categorised as global peer support were actually more closely related to diabetes-specific support. The relationship here is therefore logical, as provision of instrumental support eases self-care. This aligns with previous research in which adolescents with T1D were more than twice as likely to engage in self-care when supported by peers (Kyngäs, 2000). However, whilst instrumental support was able to significantly predict glycaemic control was significant, the same cannot be said of the findings for hypothesis 2 , which lends argument to a fundamental difference between instrumental and diabetes-specific support behaviours.

\section{Hypothesis 2: Diabetes-specific peer support}

Whilst the literature indicates an ambiguous relationship between health outcomes and diabetes-specific support, within the present participant population no overall association was indicated. Only one significant relationship between the component behaviours of diabetes-specific support could be found. This group of behaviours, named General Items, refers to behaviours which may be considered closely aligned with emotional support, as they denote encouragement and understanding. Therefore, the interpretations outlined for the results of hypothesis 1 are maintained by this finding.

Only one other study could be located noting a non-significant association between overall diabetes-specific support and glycaemic control (Smith et al., 1991), which they indicated may be due to their small sample size $(n=37)$. Similarly here, these findings may be due to Type II error given the underpowered nature of the population, though the small 
effect sizes would indicate otherwise. A lack of significant findings between diabetes-specific support and self-care is, however, more common (Greco et al., 2001; Hains et al., 2007; La Greca et al., 1995; Naar-King et al., 2006; Pendley et al., 2002).

Several interpretations of this finding are possible. Firstly, it must be remembered that the measure of diabetes-specific support relies upon perceived support. Therefore, it is possible that adolescents' perception of support is simply inaccurate due to recall bias or demand characteristics (Hains et al., 2007). Alternatively, adolescents with T1D may make poor use of the diabetes-specific support available to them from peers, either through ineffective utilisation of support behaviours or through interpreting increased support as aversive (Greco et al., 2001).

Finally, the support provided by peers may too be erroneous. Peers may lack knowledge regarding self-care, or may provide support which is inconsistent or lacking in specificity. The support provided may be neutral, or even encourage behaviours incongruent with self-care guidance (Wysocki and Greco, 2006). This potential for support behaviours which conflict with optimal self-care has been previously seen in interpreting non-significant relationships between diabetes-specific support and self-care (Naar-King et al., 2006; Pendley et al., 2002; Thomas et al., 1997), and may also be extended to glycaemic control in the present study. This growing body of research indicates that education of peers in T1D may be crucial in aiding adolescents with T1D in attaining optimal self-care, and research into the feasibility of interventions is warranted.

\section{Hypothesis 3: Glycaemic control}

Paradoxically, it was found that those with poorer glycaemic control $(>72.2 \mathrm{mmol} / \mathrm{mol}, 8.8 \%)$ reported greater diabetes-specific support. It may be that those with below average glycaemic control receive greater diabetes-specific support due to an awareness of their potential mismanagement of T1D. However, literature indicates low levels of disclosure of poor $\mathrm{HbA}_{1 \mathrm{c}}$ to peer groups, suggesting that peers would be unaware of this lack of glycaemic control and would therefore be unable to provide diabetes-specific support in this instance (Helgeson and Novak, 2007). This interpretation would align with parental support more readily, therefore, than with exclusively peer-based support.

A second interpretation of this finding can be seen in the potential for these diabetesspecific support behaviours provided by peers to be ill-informed. As with hypothesis 2, it could be suggested that the diabetes-specific support behaviours engaged in by peers are inappropriate (Naar-King et al., 2006; Pendley et al., 2002; Thomas et al., 1997). However, the DSSQ-Friends specifically related to behaviours which healthcare professionals recommend as those which will optimise improvement of glycaemic control, and therefore should eliminate potentially erroneous supportive behaviours (Pendley et al., 2002). 
A third interpretation concerns the potential for the behaviours cited by the DSSQFriends as supportive are construed by adolescents with T1D as "nagging". The behaviours previously identified as perceived as nagging (Luyckx et al., 2013; Spencer et al., 2013) align closely with those detailed by the DSSQ-Friends as supportive. Previous research has highlighted that seemingly innocuous behaviours have been interpreted as intrusive and an accusation of incapability by adolescents when delivered by parents (Seiffge-Krenke et al., 2013). It is possible that these behaviours elicit the same reaction when conveyed by peers.

This interpretation may operate via several mechanisms. It has been suggested that misconstruing parental support as nagging is related to feelings of burden and guilt, primarily at the impact that T1D has had the family (Gray et al., 2013). There is potential for this mechanism to spread to those in the wider social network, given the transfer of social support from family to peer group (Galvan et al., 2006). Adolescents may feel that minimal engagement with self-care will allow for the maintenance of their peer group as it existed prior to diagnosis, and therefore diabetes-specific behaviours serve to bring T1D to the forefront of the family dynamic once more.

An alternative, though complimentary, mechanism is highlighted by Dovey-Pearce and colleagues (2007). Qualitatively, these diabetes-specific support behaviours were said to reinforce stigma within the self-concept of the adolescents, which is rejected. Therefore, diabetes-specific support may encourage non self-management (Dovey-Pearce et al., 2007) by threatening the self-concept of the adolescent from that of a "normal" adolescent towards a sick role. This interpretation may align well with that of Gray et al.(2013), in which the "normal" adolescent self-concept is one heavily reliant on ordinary social interactions, incongruent with self-care behaviours. Therefore, at the root of the interpretation of wellintentioned support behaviours as nagging may lie a desire to be a "normal" adolescent. Further qualitative research would, however, be required in order to confirm this conjecture.

\section{Limitations}

The 90 participants recruited to the study is significantly below the minimum number to achieve acceptable statistical power. Therefore, the likelihood of a type II error must be considered when reviewing the results. However, effect size estimates alongside their confidence intervals were provided for all findings in order to protect against this.

As time since diagnosis was not collected, this cannot be assessed as a variable of interest. Previous research has shown that disease duration is influential in crucial psychosocial variables such as adjustment (Chao et al., 2014; Lehmkuhl et al., 2009).

\section{Conclusion}

Participants indicate that various types of peer support are received as a matter of course within self-care. Whilst global peer support appears to be preferred by adolescents with T1D, 
and most often associated with improved outcome measures, diabetes-specific behaviours are not perceived as supportive, and may misconstrued as a threat to the self-concept.

Ultimately, these findings suggest a convincing association between global peer support and diabetes outcomes in adolescents with T1D. However, the precise mechanism through which peer support achieves this remains questionable and requires further investigation.

\section{Declaration of Conflicting Interests}

The Author declares that there is no conflict of interest.

\section{Acknowledgements}

My deepest thanks go to Dr Stuart Allen, Dr Mary Dobson and Prof Jorg Huber for their support and advice throughout this research. These findings were presented at the British Psychological Society's Division of Health Psychology Conference in September 2015.

\section{References}

Bearman KJ and La Greca AM (2002) Assessing friend support of adolescents' diabetes care: The diabetes social support questionnaire-friends version. Journal of Pediatric Psychology 27(5): 417-28. Available from:

http://www.ncbi.nlm.nih.gov/pubmed/12058006.

Chao A, Whittemore R, Minges KE, et al. (2014) Self-management in early adolescence and differences by age at diagnosis and duration of type 1 diabetes. The Diabetes educator 40(2): 167-77. Available from: http://www.ncbi.nlm.nih.gov/pubmed/24470042.

Collins WA and Steinberg I (2006) Adolescent development in interpersonal context. 6th ed. In: Damon W, Lerner R, and Eisenberg N (eds), The Handbook of Child Psychology, Hoboken, New Jersey.

DAFNE Study Group (2002) Training in flexible, intensive insulin management to enable dietary freedom in people with type 1 diabetes: dose adjustment for normal eating (DAFNE) randomised controlled trial. BMJ (Clinical research ed.) 325(7367): 746.

Dovey-Pearce G, Doherty Y and May C (2007) The influence of diabetes upon adolescent and young adult development: a qualitative study. British Journal of Health Psychology 12(1): 75-91. Available from: http://www.ncbi.nlm.nih.gov/pubmed/17288667 (accessed 12 March 2013).

Galvan A, Hare TA, Parra CE, et al. (2006) Earlier development of the accumbens relative to orbitofrontal cortex might underlie risk-taking behavior in adolescents. Journal of Neuroscience 26: 6885-6892.

Garamszegi LZ (2006) Comparing effect sizes across variables: Generalization without the need for Bonferroni correction. Behavioral Ecology 17(4): 682-687.

Gray WN, Dolan LM and Hood KK (2013) Impact of blood glucose monitoring affect on 
family conflict and glycemic control in adolescents with type 1 diabetes. Diabetes Research and Clinical Practice 99(2): 130-135.

Greco P, Shroff Pendley J, McDonnell K, et al. (2001) A peer group intervention for adolescents with type 1 diabetes and their best friends. Society of Pediatric Psychology 26(8): 485-490.

Hains AA, Berlin KS, Davies WH, et al. (2007) Attributions of adolescents with type 1 diabetes related to performing diabetes care around friends and peers: The moderating role of friend support. Journal of Pediatric Psychology 32: 561-570.

Hanna KM (2006) Existing measures of diabetes-specific support for use with adolescents with diabetes. The Diabetes Educator 32(5): 741-50. Available from: http://www.ncbi.nlm.nih.gov/pubmed/16971707 (accessed 8 March 2013).

Hanna KM, Weaver MT, Stump TE, et al. (2013) Initial findings: Primary diabetes care responsibility among emerging adults with type 1 diabetes post high school and move out of parental home. Child: Care, Health and Development 39(1): 61-8. Available from: http://www.ncbi.nlm.nih.gov/pubmed/22017460 (accessed 18 October 2013). Health and Social Care Information Centre (2016) National Diabetes Insulin Pump Audit Report , 2013-15. Available from: http://www.hscic.gov.uk/catalogue/PUB20436/natidiab-insu-pump-audi-rep-2013-15.pdf.

Hedges L V (2008) What Are Effect Sizes and Why Do We Need Them? Child Development Perspectives 2(3): 167-171. Available from: <Go to ISI>://000270262600008\nhttp://onlinelibrary.wiley.com/store/10.1111/j.17508606.2008.00060.x/asset/j.17508606.2008.00060.x.pdf?v=1\&t=i1 i6kdz0\&s=810af0b6d228f4da07c755f95cdd9e9ff8b77 896.

Helgeson VS and Novak SA (2007) IIIness centrality and well-being among male and female early adolescents with diabetes. Journal of pediatric psychology 32(3): 260-72. Available from: http://www.ncbi.nlm.nih.gov/pubmed/16837739 (accessed 8 April 2014). Helgeson VS, Reynolds KA, Escobar O, et al. (2007) The role of friendship in the lives of male and female adolescents: Does diabetes make a difference? The Journal of Adolescent Health 40(1): 36-43. Available from:

http://www.ncbi.nlm.nih.gov/pubmed/17185204 (accessed 12 March 2013).

Helgeson VS, Lopez LC and Kamarck T (2009) Peer Relationships and Diabetes :

Retrospective and Ecological Momentary Assessment Approaches. Health Psychology 28(3): 273-282.

Helgeson VS, Siminerio L, Escobar O, et al. (2009) Predictors of metabolic control among adolescents with diabetes: A 4-year longitudinal study. Journal of Pediatric Psychology 34(3): 254-270. 
Helgeson VS, Palladino DK, Reynolds KA, et al. (2013) Relationships and health among emerging adults with and without type 1 diabetes. Health Psychology ePub. Available from: http://www.ncbi.nlm.nih.gov/pubmed/23914816 (accessed 24 October 2013).

Hinder S and Greenhalgh T (2012) 'This does my head in'. Ethnographic study of selfmanagement by people with diabetes. BMC Health Services Research, BioMed Central Ltd 12(1): 83. Available from: http://www.biomedcentral.com/1472-6963/12/83.

House JS (1981) Work Stress and Social Support. Reading, MA: Addison-Wesley. Jacobson AM, Braffett BH, Cleary PA, et al. (2013) The Long-Term Effects of Type 1 Diabetes Treatment and Complications on Health-Related Quality of Life. Diabetes Care 36(10): 3131-3138.

Kichler JC, Kaugars AS, Maglio K, et al. (2012) Exploratory analysis of the relationships among different methods of assessing adherence and glycemic control in youth with type 1 diabetes mellitus. Health Psychology 31(1): 35-42.

Kyngäs H (2000) Compliance of adolescents with diabetes. Journal of Pediatric Nursing 15(4): 260-7. Available from: http://www.ncbi.nlm.nih.gov/pubmed/10969500 (accessed 12 March 2013).

La Greca AM, Auslander WF, Greco P, et al. (1995) I get by with a little help from my family and friends: Adolescents' support for diabetes care. Journal of Pediatric Psychology 20: 449-476.

Lehmkuhl HD, Merlo LJ, Devine K, et al. (2009) Perceptions of type 1 diabetes among affected youth and their peers. Journal of Clinical Psychology in Medical Settings 16(3): 209-15. Available from:

http://www.pubmedcentral.nih.gov/articlerender.fcgi?artid=2866191\&tool=pmcentrez\&re ndertype=abstract (accessed 12 March 2013).

Luyckx K, Seiffge-Krenke I, Missotten L, et al. (2013) Parent-adolescent conflict, treatment adherence and glycemic control in Type 1 diabetes: The importance of adolescent externalising symptoms. Psychology \& Health 28(9): 1082-1097.

Naar-King S, Podolski C-L, Ellis D a, et al. (2006) Social ecological model of illness management in high-risk youths with type 1 diabetes. Journal of Consulting and Clinical Psychology 74(4): 785-9. Available from:

http://www.ncbi.nlm.nih.gov/pubmed/16881786 (accessed 12 March 2013).

National Diabetes Audit (2014) National Diabetes Audit 2012-2013.

National Institute for Health and Care Excellence (2015) NG18: Diabetes (type 1 and type 2) in children and young people: diagnosis and management. Available from: http://www.nice.org.uk/guidance/ng18.

Palladino DK and Helgeson VS (2012) Friends or foes? A review of peer influence on selfcare and glycemic control in adolescents with type 1 diabetes. Journal of Pediatric 
Psychology 37(5): 591-603.

Pendley JS, Kasmen LJLJ, Miller DLDL, et al. (2002) Peer and family support in children and adolescents with type 1 diabetes. Journal of Pediatric Psychology 27(5): 429-438.

Peterson MS, Lawman HG, Wilson DK, et al. (2012) The Association of Self-Efficacy and Parent Social Support on Physical Activity in Male and Female Adolescents. Health Psychology 32(6): 666-674.

Pinquart M and Pfeiffer JP (2011) Associations of Extroversion and Parental Overprotection with Forming Relationships with Peers Among Adolescents with and without Visual Impairments. Journal of Visual Impairment \& Blindness 105(2): 96-107.

Schulz U and Schwarzer R (2003) Soziale Unterstu“" tzung bei der Krankheitsbewa"ltigung: Die Berliner Social Support Skalen (BSSS) [Social support and coping with illness: The Berlin Social Support Scales [BSSS]). Diagnostica 49: 73-82.

Seiffge-Krenke I, Laursen B, Dickson DJ, et al. (2013) Declining metabolic control and decreasing parental support among families with adolescents with diabetes: The risk of restrictiveness. Journal of Pediatric Psychology 38(5): 518-530.

Smith MS, Mauseth R, Palmer JP, et al. (1991) Glycosylated hemoglobin and psychological adjustment in adolescents with diabetes. Adolescence VO - 26, Libra Publishers, Inc. (101): 31. Available from: http://search.ebscohost.com/login.aspx?direct=true\&db=edsgao\&AN=edsgcl.10707207 \&site=eds-live.

Spencer JE, Cooper HC and Milton B (2013) The lived experiences of young people (13-16 years) with Type 1 diabetes mellitus and their parents - a qualitative phenomenological study. Diabetic Medicine 30(1): 17-24.

Thomas AM, Peterson L and Goldstein D (1997) Problem solving and diabetes regimen adherence by children and adolescents with IDDM in social pressure situations: A reflection of normal development. Journal of Pediatric Psychology 22(4): 541-61. Available from: http://www.ncbi.nlm.nih.gov/pubmed/9302851.

Umberson D, Crosnoe R and Reczek C (2011) Social relationships and health behavior across life course. Annual Review of Sociology 36: 139-157.

World Health Organisation and International Diabetes Federation (2006) Definition and diagnosis of diabetes mellitus and intermediate hyperglycaemia. Available from: http://www.who.int/diabetes/publications/Definition and diagnosis of diabetes_new.pdf. Wysocki T and Greco P (2006) Social support and diabetes management in childhood and adolescence: Influence of parents and friends. Current Diabetes Reports 6(2): 117-22. Available from: http://www.ncbi.nlm.nih.gov/pubmed/16542622. 
Annex: Acceptance Information

From: onbehalfof+editorjhp+gmail.com@manuscriptcentral.com On Behalf Of editorjhp@gmail.com Sent: 26 April 2016 09:29

To: Emily Doe <emily.doe@buckingham.ac.uk>

Subject: Journal of Health Psychology - Decision on Manuscript ID JHP-16-0100

26-Apr-2016

Dear Miss Doe:

Manuscript ID JHP-16-0100 entitled "An analysis of the relationships between peer support and diabetes outcomes in adolescents with type 1 diabetes" which you submitted to the Journal of Health Psychology, has been reviewed. The comments of the reviewer are included at the bottom of this letter.

The reviewer has recommended publication, but also suggests some revisions to your manuscript. Therefore, I invite you to respond to the comments and revise your manuscript. I hope that you find their comments constructive and helpful. A second reviewer was invited but has been too late to consider.

To revise your manuscript, log into https://mc.manuscriptcentral.com/ihealthpsychology and enter your Author Center, where you will find your manuscript title listed under "Manuscripts with Decisions." Under "Actions," click on "Create a Revision." Your manuscript number has been appended to denote a revision.

You will be unable to make your revisions on the originally submitted version of the manuscript. Instead, revise your manuscript using a word processing program and save it on your computer. Please also highlight the changes to your manuscript within the document by using the track changes mode in MS Word or by using bold or colored text. Once the revised manuscript is prepared, you can upload it and submit it through your Author Center.

When submitting your revised manuscript, you will be able to respond to the comments made by the reviewers in the space provided. You can use this space to document any changes you make to the original manuscript. In order to expedite the processing of the revised manuscript, please be as specific as possible in your response to the reviewers.

IMPORTANT: Your original files are available to you when you upload your revised manuscript. Please delete any redundant files before completing the submission.

Because we are trying to facilitate timely publication of manuscripts submitted to the Journal of Health Psychology, your revised manuscript should be uploaded as soon as possible. If it is not possible for you to submit your revision in a reasonable amount of time, we may have to consider your paper as a new submission.

Once again, thank you for submitting your manuscript to the Journal of Health Psychology and I look forward to receiving your revision.

With best wishes,

David F Marks PhD

Editor

Journal of Health Psychology

editorjhp@gmail.com 